\title{
License plate recognition for campus auto-gate system
}

\author{
Nur Liyana Yaacob, Ammar Ahmed Alkahtani, Fuad M. Noman, Ahmad Wafi Mahmood Zuhdi, \\ Dhuha Habeeb \\ Institute of Sustainable Energy (ISE), Universiti Tenaga Nasional (UNITEN), Malaysia
}

\begin{tabular}{|c|c|}
\hline Article Info & ABSTRACT \\
\hline Article history: & Automatic licence plate recognition (LPR) has been a subject of study for the \\
\hline Received May 25, 2020 & $\begin{array}{l}\text { last few decades. Considering the recent advancements in machine learning } \\
\text { methods and portable devices, this increasingly attracting researchers? }\end{array}$ \\
\hline Revised Jul 27, 2020 & interest to provide more reliable LPR systems. Several LPR techniques have \\
\hline Accepted Aug 13, 2020 & $\begin{array}{l}\text { been reported in the literature in different intelligent transportation } \\
\text { applications and surveillance systems, and yet a ropust LPR system remains }\end{array}$ \\
\hline Keywords: & $\begin{array}{l}\text { a challenging research task. Because the performance of current techniques is } \\
\text { subject to several factors and local conditions, this paper aims to explore the }\end{array}$ \\
\hline Campus auto-gate system & use of LPR in a specific application; i.e. Automatic plate recognition to \\
\hline Image processing & $\begin{array}{l}\text { monitor the entry and exit of vehicles at the university campus gates. } \\
\text { Implementing an auto-gate system is an important application for a smooth }\end{array}$ \\
\hline License plate recognition & $\begin{array}{l}\text { control of flowing traffic especially during peak hours. We propose an } \\
\text { automated system with the ability to capture, verify and recognize the license } \\
\text { plates using image processing-based techniques. The system is aimed to } \\
\text { work alongside existing access cards and other gate remote controls. } \\
\text { Experimental evaluation of the system reveals a detection accuracy of } \\
91.58 \% \text {, a successful plate number segmentation rate of } 91 \% \text { and } 80 \% \\
\text { accuracy of plate recognition. }\end{array}$ \\
\hline
\end{tabular}

This is an open access article under the CC BY-SA license.

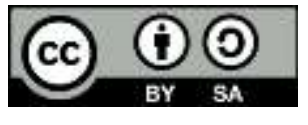

Corresponding Author:

Ammar Alkahtani

Institute of Sustainable Energy

Universiti Tenaga National, Malaysia

Email: ammar@uniten.edu.my

\section{INTRODUCTION}

License plate recognition (LPR) is one of image processing techniques that process the image of the license plate to recognize the vehicle identity. Numerous research works on automatic LPR have been carried out in the few past decades and are still ongoing for further improvements. LPR has been widely used in many different applications such as auto toll collection, traffic monitoring, auto gate systems and many other intelligent and transportation systems. It becomes more important with the increased number of car thefts and traffic violation incidents worldwide. According to statistics published by The Star newspaper, there are on average 62 vehicles stolen each day in Malaysia [1].

A gate control system is one of the applications that can utilize LPR systems for controlling the entrance for security as well as convenience reasons. In auto-gate systems, the LPR identifies and verifies the vehicle number, then decides whether to open the gate or not. This can be used as an alternative to other methods of access control, such as access cards, which may incur a high cost and cause a traffic congestion, especially during peak hours. Access card, however, can still be used in the case of the failure of LPR based auto-gate systems.

In Malaysia, vehicle license plates are standardized by the Malaysian road transport department (JPJ). There are only three allowed forms of vehicle license plates [2]: 
a) White letters and numbers are affixed or embossed over black plates.

b) White letters and numbers are affixed or embossed over red plates for embassies' vehicles, United Nations' vehicles and the international natural rubber association's vehicles.

c) Black letters and numbers are affixed or embossed over white plates for taxis or rental cars.

There are two types of patterns in which the characters on the plate can be arranged; i.e. in a single or double row. Figure 1 show examples of the Malaysian license plate specifications. License plate characters consist of a combination of letters and numbers. In Malaysia, most license plates start with three letters followed by four numbers. However, the numbers of each plate vary depending on the region where the vehicles are registered. Besides, there are custom license plate numbers containing fewer characters than the standard numbers. These custom plate numbers can be bought by the vehicle owner at different charges. The Putrajaya's car license number and Jaguh typed motorcycle license number are two of the examples of custom license plate number.

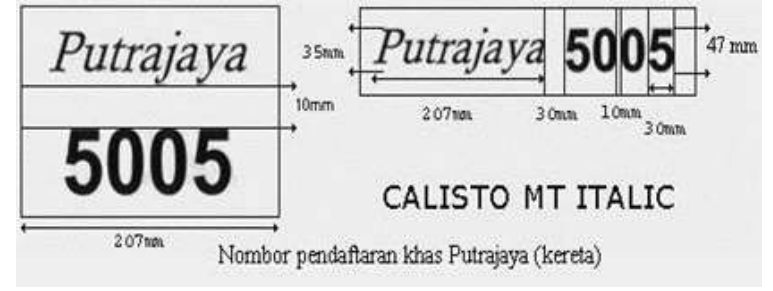

(a)

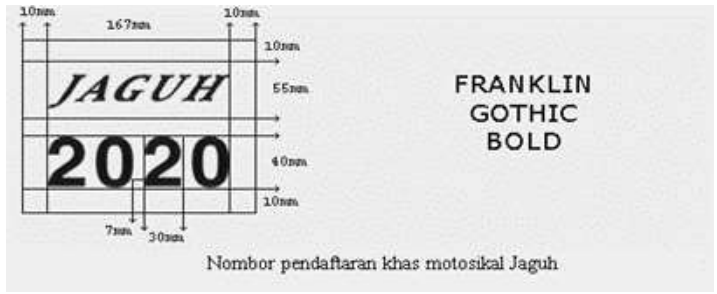

(b)

Figure 1. Example of Malaysian plate types. (a) Example of Putrajaya's car license number;

(b) motorcycle license number-Jaguh type [2]

\section{RELATED WORK}

Many character recognition techniques have been utilized to recognize the characters on the license plate, such as template matching, neural networks, hidden Markov models, fuzzy logic and support vector machine. Other methods such as k-neares neighbour $(\mathrm{KNN})$ has also been used for license plate numbers recognition [3, 4]. Figure 2 shows a summary of the techniques used to identify characters. The most used techniques in the literature for character recognition are template matching and neural networks and thus we limit the literature review to these two techniques.

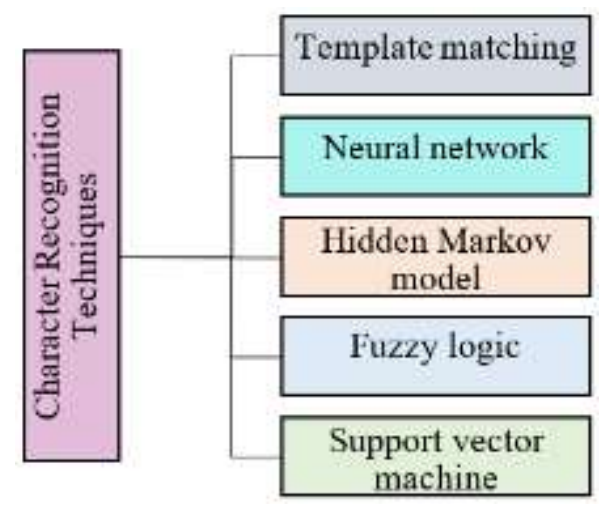

Figure 2. Character recognition techniques

\subsection{Template matching}

Template matching is a method used in image processing for detecting areas of an image that match the template image. It is done by calculating the correlation coefficient of both input image and template images. The highest correlation coefficient value produces the best match. In Table 1, selected research papers that employ the technique of template matching are presented. For each work, the table lists the methods of plate detection and segmentation, the speed of recognition, and a set of performance indicators, including the success rates of license plate detection (LPD), segmentation (Seg.), character recognition (CR) and the overall accuracy. 


\subsection{Neural network}

Neural networks, also known as artificial neural networks (ANNs) are one of the computing systems that are inspired by the structure of the human information processing system; i.e. the brain. An ANN is made up of a number of interconnected nodes, called neurons, which are structured in layers as shown in Figure 3. ANN has the ability to learn, recognize patterns and make decisions by the training process. Table 2 shows some of the proposed techniques of LPR from the literature, which utilize neural networks for character recognition. The deep neural network has also been used in the literature [5]. However, the deep architectures of neural networks are not considered in this paper. Similar to template matching methods discussed in Table 1, we consider the accuracy achieved in plate extraction, character segmentation, and recognition. We also list the employed techniques of detection and segmentation.

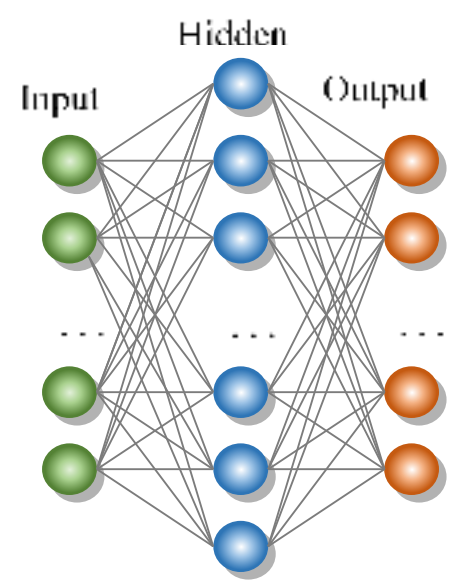

Figure 3. Neural network structure

Table 1. Selected research papers employing template matching

\begin{tabular}{|c|c|c|c|c|c|c|c|}
\hline Ref. & $\begin{array}{l}\text { License plate detection (LPD) } \\
\text { method }\end{array}$ & Segmentation (S) method & $\begin{array}{l}\text { Time } \\
(\mathrm{sec})\end{array}$ & $\begin{array}{l}\text { LPD } \\
\text { success } \\
\text { rate } \\
(\%) \\
\end{array}$ & $\begin{array}{l}\text { Seg. } \\
\text { success } \\
\text { rate }(\%)\end{array}$ & $\begin{array}{l}\text { CR success } \\
\text { rate }(\%)\end{array}$ & $\begin{array}{l}\text { Overall } \\
\text { success } \\
\text { rate }(\%)\end{array}$ \\
\hline [7] & Gradient analysis & $\mathrm{n} / \mathrm{a}$ & $1.1 \mathrm{~s}$ & $\mathrm{n} / \mathrm{a}$ & $\mathrm{n} / \mathrm{a}$ & $\mathrm{n} / \mathrm{a}$ & 91 \\
\hline$[8]$ & $\begin{array}{l}\text { Vertical edge detection, seed- } \\
\text { filling algorithm }\end{array}$ & $\begin{array}{l}\text { Vertical projection \& count } \\
\text { number of pixels }\end{array}$ & $\mathrm{n} / \mathrm{a}$ & 96.22 & 94.04 & 95.24 & $\mathrm{n} / \mathrm{a}$ \\
\hline [9] & $\begin{array}{l}\text { Morphological operations and } \\
\text { projection searching } \\
\text { algorithm }\end{array}$ & Vertical projection & $\mathrm{n} / \mathrm{a}$ & 93.2 & 95 & 82.3 & $\mathrm{n} / \mathrm{a}$ \\
\hline$[10]$ & $\begin{array}{l}\text { Edge detection \& Smearing } \\
\text { algorithm }\end{array}$ & $\begin{array}{l}\text { Smearing, filtering, } \\
\text { morphological }\end{array}$ & $\mathrm{n} / \mathrm{a}$ & 97.6 & 96 & 98.8 & $\mathrm{n} / \mathrm{a}$ \\
\hline [11] & $\mathrm{n} / \mathrm{a}$ & $\mathrm{n} / \mathrm{a}$ & $1.6 \mathrm{~s}$ & $\mathrm{n} / \mathrm{a}$ & $\mathrm{n} / \mathrm{a}$ & $\mathrm{n} / \mathrm{a}$ & 90 \\
\hline$[14]$ & Canny detector and Hough & $\begin{array}{l}\text { Smearing and dilation } \\
\text { operation }\end{array}$ & 0.9 & 94.11 & $\mathrm{n} / \mathrm{a}$ & 90.62 & 89.70 \\
\hline$[15]$ & $\begin{array}{l}\text { Connected component } \\
\text { analysis }\end{array}$ & Bounding box & 0.298 & 80 & 87.5 & 97 & 88.16 \\
\hline$[16]$ & Canny method & $\begin{array}{l}\text { Horizontal and vertical } \\
\text { projection }\end{array}$ & $\mathrm{n} / \mathrm{a}$ & $\mathrm{n} / \mathrm{a}$ & $\mathrm{n} / \mathrm{a}$ & $\mathrm{n} / \mathrm{a}$ & 91 \\
\hline$[17]$ & $\mathrm{n} / \mathrm{a}$ & $\begin{array}{l}\text { Otsu's method \& Connected } \\
\text { component }\end{array}$ & $\mathrm{n} / \mathrm{a}$ & $\mathrm{n} / \mathrm{a}$ & $\mathrm{n} / \mathrm{a}$ & $\mathrm{n} / \mathrm{a}$ & 98.07 \\
\hline$[18]$ & $\begin{array}{l}\text { Sobel vertical edge, } \\
\text { morphological, bounding box }\end{array}$ & $\begin{array}{l}\text { Horizontal and vertical } \\
\text { segmentation }\end{array}$ & $\mathrm{n} / \mathrm{a}$ & $\mathrm{n} / \mathrm{a}$ & $\mathrm{n} / \mathrm{a}$ & $\mathrm{n} / \mathrm{a}$ & 80 \\
\hline [19] & Smearing algorithm & $\begin{array}{l}\text { Row and column } \\
\text { segmentation }\end{array}$ & $\mathrm{n} / \mathrm{a}$ & 97.4 & 96.0 & 76.0 & $\mathrm{n} / \mathrm{a}$ \\
\hline
\end{tabular}


Table 2. Selected research papers employing neural networks

\begin{tabular}{|c|c|c|c|c|c|c|c|}
\hline Ref. & $\begin{array}{l}\text { License plate detection (LPD) } \\
\text { method }\end{array}$ & Segmentation (S) method & $\begin{array}{l}\text { Time } \\
(\mathrm{sec})\end{array}$ & $\begin{array}{l}\text { LPD } \\
\text { success } \\
\text { rate }(\%)\end{array}$ & $\begin{array}{l}\text { S success } \\
\text { rate }(\%)\end{array}$ & $\begin{array}{l}\mathrm{CR} \\
\text { success } \\
\text { rate }(\%)\end{array}$ & $\begin{array}{l}\text { Overall } \\
\text { success } \\
\text { rate }(\%) \\
\end{array}$ \\
\hline [20] & Grey scale processing & $\begin{array}{l}\text { Lateral histogram } \\
\text { analysis }\end{array}$ & 15 & 99 & 99 & 98 & 80 \\
\hline [21] & Connected Component analysis & $\mathrm{n} / \mathrm{a}$ & 4 & 100 & $\mathrm{n} / \mathrm{a}$ & 92.5 & $\mathrm{n} / \mathrm{a}$ \\
\hline [22] & $\begin{array}{l}\text { Morphological \& modified Hough } \\
\text { Transform }\end{array}$ & Bounding box & $\mathrm{n} / \mathrm{a}$ & $\mathrm{n} / \mathrm{a}$ & $\mathrm{n} / \mathrm{a}$ & $\mathrm{n} / \mathrm{a}$ & 95 \\
\hline$[23]$ & Multiple interlacing method & $\mathrm{n} / \mathrm{a}$ & 2 & $\mathrm{n} / \mathrm{a}$ & $\mathrm{n} / \mathrm{a}$ & $\mathrm{n} / \mathrm{a}$ & 95 \\
\hline [24] & Texture-based approach & Connected components & $\mathrm{n} / \mathrm{s}$ & 92.1 & 90.5 & 93.2 & $\mathrm{n} / \mathrm{a}$ \\
\hline [25] & $\begin{array}{l}\text { Canny edge detector \& } \\
\text { Morphological operation }\end{array}$ & $\mathrm{n} / \mathrm{a}$ & 3 & $97 \%$ & $\mathrm{n} / \mathrm{a}$ & $\mathrm{n} / \mathrm{a}$ & $\mathrm{n} / \mathrm{a}$ \\
\hline [26] & $\begin{array}{l}\text { Sobel's edge detection algorithm } \\
\text { Gabor filter, threshold, and }\end{array}$ & Horizontal scanning & $\mathrm{n} / \mathrm{a}$ & 94 & 96 & 98 & $\mathrm{n} / \mathrm{a}$ \\
\hline [27] & $\begin{array}{l}\text { connected component labelling } \\
\text { algorithm }\end{array}$ & $\mathrm{n} / \mathrm{a}$ & 0.5 & 91.7 & 87.16 & 90.93 & $\mathrm{n} / \mathrm{a}$ \\
\hline [28] & $\begin{array}{l}\text { Otsu's thresholding method \& } \\
\text { license plate features }\end{array}$ & $\begin{array}{l}\text { Vertical and horizontal } \\
\text { histogram }\end{array}$ & 0.1 & 91 & $\mathrm{n} / \mathrm{a}$ & 96.5 & $\mathrm{n} / \mathrm{a}$ \\
\hline [29] & $\begin{array}{l}\text { Edge detection, image } \\
\text { subtraction, mathematical } \\
\text { morphology, radon transform, and } \\
\text { interpolation }\end{array}$ & $\begin{array}{l}\text { Peak-to-valley method } \\
\text { and statistical parameters }\end{array}$ & 0.25 & 97.13 & 98.21 & 97.25 & 97.43 \\
\hline
\end{tabular}

\section{PROPOSED METHOD}

The proposed automatic LPR system consists of three main steps, which are (i) license plate localization, (ii) character segmentation and (iii) character recognition as shown in Figure 4. The proposed system starts with reading the input image and then followed by locating and extracting the region of interest which contains the license plate in the processed image. The license plate will be skew corrected automatically. Since Malaysian's license plate has two types of patterns, the next step is to identify the license plate pattern. From the extracted license plate image, the characters in the image will be segmented one by one. Lastly, each character will be compared with the available stored templates to recognize each of the characters.

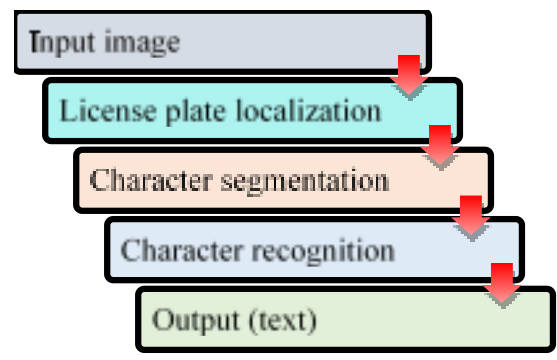

Figure 4. Process flow of the proposed LPR system

\subsection{License plate recognition}

There are six phases in the license plate localization stage which are pre-processing, edge detection, erosion, image closing, image binarization with removing unwanted pixels and locating license plate region as shown in Figure 5.

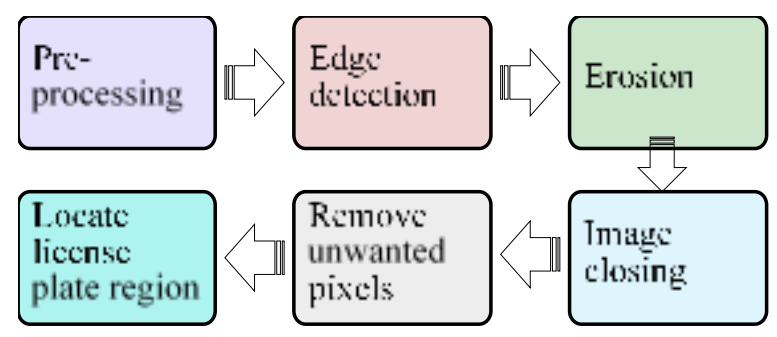

Figure 5. Six phases of the license plate localization process 
Pre-processing is the processes of image enhancement to improve the image quality before passing it to the next process. Some examples of image enhancement methods include image filtering and sharpening. In the pre-processing stage, the input image is first cropped with fixed positions on the image using the imcrop function in MATLAB. The resolution of the image is reduced from $3264 \times 2448$ to $969 \times$ 445. Reducing the image resolution reduces the computing time as reported in [6]. Besides, cropping the image eliminates the complex background which will ease the next process to locate the vehicle plate region. Figure 6(a) shows the original input image. The image is then converted from RGB format to gray-scale. Figure 6(b) shows the cropped image that has been converted to grayscale.

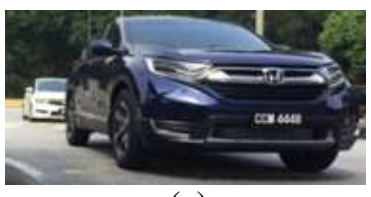

(a)

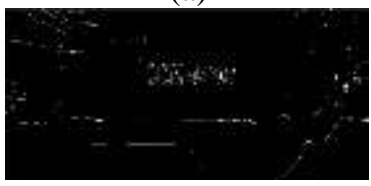

(c)

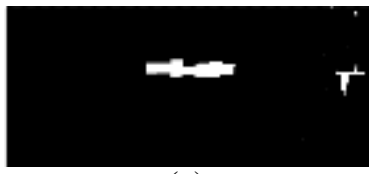

(e)

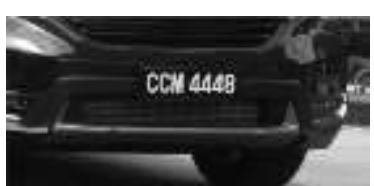

(b)

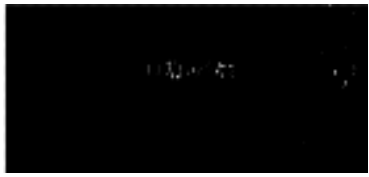

(d)

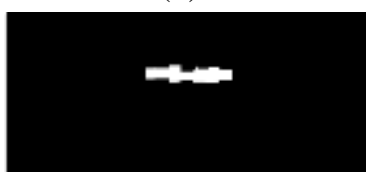

(f)

Figure 6. (a)Original input image, (b) Gray-scale cropped image, (c) Edge detection using Sobel operator, (d) Image erosion, (e) Image closing, (f) Pixels less than 2000 is removed

In the edge detection process, Sobel operator is used although it produces less accuracy detection compared to Canny operator [30,31]. This helps to reduce the computing time to eliminate the unwanted edges. Figure 7(c) shows the edge detection using the Sobel operator. Then, the image is eroded with a structuring element, a matrix of $1 \mathrm{~s}$. This process is to eliminate the horizontal edges. It is done by replacing the white (1) pixel to black (0) pixel if the structuring element does not entirely overlap with the white pixels. Figure 6(d) shows the eroded image. After that, the eroded image is closed with a rectangle-shaped structuring element as depicted in Figure 6(e). The next process is removing the unwanted pixels. The license plate region is usually the largest pixels. The pixel values of the license plate were estimated to be more than 2000 pixels. Thus, all the connected components in the binary image which have fewer than 2000 pixels are removed. Figure 6(f) shows the resulted image.

The license plate region is located by finding the white pixels region in the binary image. The maximum and the minimum of the column and row dimensions that contain white pixel (1) are iteratively calculated. The license plate region on the original image is cropped once all the rows and columns values are calculated. Figure 7 shows the license plate that was extracted from the actual image.

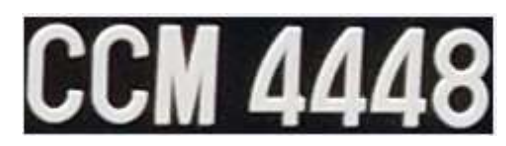

Figure 7. Extracted license plate

\subsection{Character segmentation}

In the character segmentation stage, there are four phases which are pre-processing, skew correction, row detection and lastly followed by character segmentation as shown in Figure 8. The output image from the license plate localization stage is processed using the morphological operation to enhance the image before passing to the next process. The morphological operations used are dilation and fill image. 
These operations are used to make the characters connect to form one big object. Figure 9(a) shows the image dilated after it is converted from gray-scale image to binary image. The process is followed by filling the holes in the character as shown in Figure 9(b). The image is then dilated multiple times to make sure the characters are all connected as in Figure 9(c). In this system, the image is dilated six times. The empty spaces between the characters were taken into consideration for the dilation values. The more distance between the character means more dilation values.

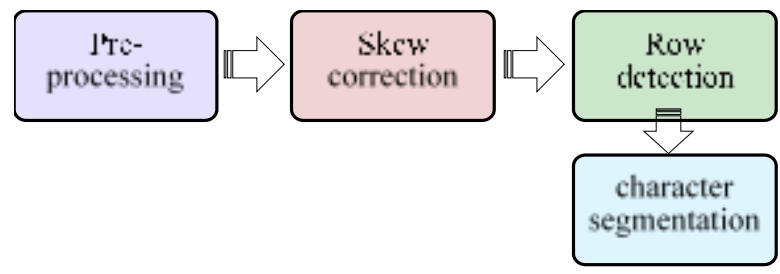

Figure 8. Four phases in character segmentation process

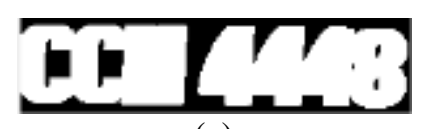

(a)

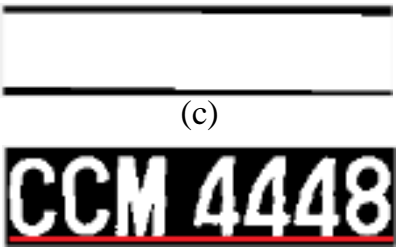

(e)

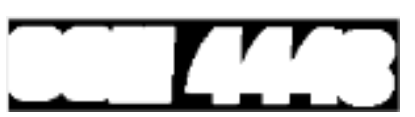

(b)

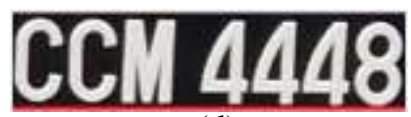

(d)

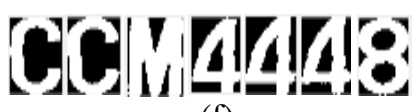

(f)

Figure 9. (a) Dilated image, (b) Holes are filled, (c) Multiple dilated image, (d) Skewed license plate,

(e) Skew corrected license plate, (f) Segmented characters

Skew correction is the process to correct the tilted license plate. This is to increase the accuracy rate of the character recognition. In this system, Regionprops function is used to calculate the skewness angle. The image is then rotated based on the calculated angle. By comparing both Figure 9 (d) and (e) with the red line as the skew indicator, it can be seen that Figure 9 (e) is skew corrected.

Character segmentation is the process whereby each character is extracted individually before the character recognition process. Since Malaysian license plate has two type of pattern, each registered vehicle may use a single row or double row type. Before proceeding to the segmentation part, it is a need to separate the two rows. In this system, bwlabel function is used, which labels the connected components of the image. In other words, this function counts the connected components and lists them.

After that, each character is cropped from the skew corrected license plate image. It is done by identifying the maximum and minimum row and column dimensions of each labelled connected components. Each cropped character is normalized to a size of $42 \times 24$ pixels, which is the same size of the template that will be used to perform the correlation between both templates and cropped characters from the license plate. Figure 10(f) shows the segmented characters that have been extracted from the skew corrected license plate image.

\subsection{Character recognition}

After the character segmentation stage, template matching method is utilized in the character recognition stage. The main operation that is used for the recognition is the correlation in two dimensions. This operation gives a value of the similarity between two matrices (images). The function corr 2 in the MATLAB is according to the following (1):

$$
r=\frac{\sum_{m} \sum_{n}\left(A_{m n}-\bar{A}\right)\left(B_{m n}-\bar{B}\right)}{\sqrt{\left[\sum_{m} \sum_{n}\left(A_{m n}-\bar{A}\right)^{2}\right]\left[\sum_{m} \sum_{n}\left(B_{m n}-\bar{B}\right)^{2}\right]}}
$$


where $\bar{A}$ and $\bar{B}$ are the scalar mean of the two-dimensional images $A$ and $B$, respectively. The $m$ and $n$ are the dimensions (height and width) of the correlated images.

Once all the correlations are calculated, the output text of the license plate will be stored in a text editor. Since there are many vehicles use non-standard fonts, the fonts that have been encountered were used in the templates.

\subsection{Auto-gate system}

According to the prototype which is designed to work in a similar way to that in Figure 10, an IR sensor is used to detect the motion of the car and the camera will be triggered to capture the vehicle image. The image will be processed according to the previously explained mechanism and if the vehicle number is registered within the database of the university, the gate will open. Otherwise, if the plate number of the vehicle is not registered or recognized incorrectly, a buzzer will beep to notify the guard for further actions.

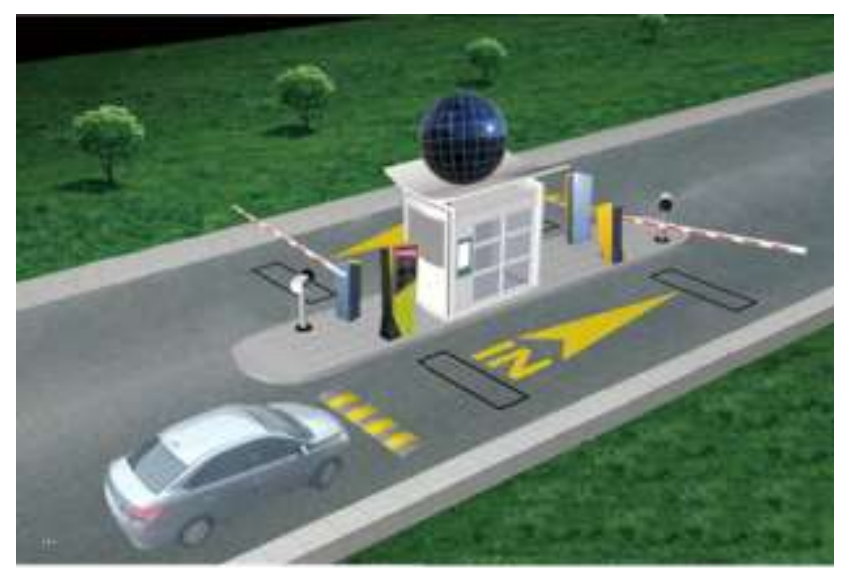

Figure 10. A prototype of automated gate opening system

\section{EXPERIMENTAL RESULTS}

The MATLAB used in this experiment to test the performance of the system is R2017b. The system is implemented with PC processor of Intel ${ }^{\circledR}$ Core $^{\mathrm{TM}}$ i5-3210M CPU @ $2.50 \mathrm{GHz} 2.50 \mathrm{GHz}, \mathrm{RAM} 8.00 \mathrm{~GB}$, Windows 7 Professional 64-bit Operating System. The test images were taken with an 8MP iPhone camera. The camera used to capture the test images was put in a fix position so that all the vehicles are captured at almost the same distance. A total of 95 images were used as the input images including some of the images that were used to extract the templates to test the proposed system's performance. Table 3 shows the results of the proposed system's performance. From the table, it can be seen that the performance of the system was evaluated by each main stage. Firstly, the 95 input images were tested on the license plate localization stage and the successful test images were then tested on the character segmentation stage. The successful test images of the character segmentation stage were tested on the character recognition process. That is the reason why the input test images were reduced from 95 to 89 and 89 to 83 for license plate localization to character segmentation and character segmentation to character recognition respectively. From the table, the success rate for the license plate localization, character segmentation and character recognition are $93.68 \%$, 93.25\% and $84.33 \%$ respectively. MATLAB stopwatch timer was used measure the computational time and the average computational time for the whole system is found to be 0.452 seconds.

Table 3. The Performance of the proposed system

\begin{tabular}{lccc}
\hline & Successful test images & Error rate & Success rate \\
\hline License Plate Localization & $89 / 95$ & $6.32 \%$ & $93.68 \%$ \\
Character Segmentation & $83 / 89$ & $6.75 \%$ & $93.25 \%$ \\
Chatacter Recognition & $70 / 83$ & $15.67 \%$ & $84.33 \%$ \\
\hline
\end{tabular}

One of the factors that affect the license plate localization performance is complex background. Eliminating horizontal edges would not work well with images that have a complex background because it 
might leave large vertical edges residue from the background. This will cause a problem in locating the license plate region because the system might locate the wrong white pixels region which from the complex background. Besides that, the license plate localization performance will also be affected if the vehicle has text stickers on the vehicle body or vehicle model written on the front body, for example, Ford Ranger and Range Rover. In addition, a license plate that has registration number written too far apart from each other as in Figure 11 will be mistakenly located. This is because characters region will not be connected when the image closing is performed because of the wide spaces. The system only manages to locate the "WC" of the registration number as can be seen in Figure 11.

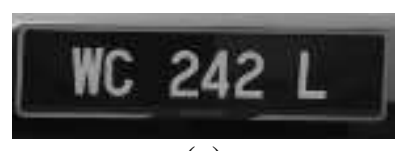

(a)

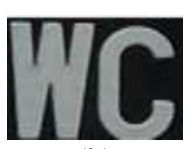

(b)

Figure 11. Example of plate number wrong detection. (a) Registration number with wide spaces.

(b) Wrong detection with partial extraction of plate number region

For the character segmentation stage, the performance will be affected if the characters are too close to each other. The system will segment the characters that are very close to each other as one character. In the character recognition stage, there are some misclassification occurred. This is because of the resemblances between the characters for instance 8 and B, 0 and Q, 6 and 9, and $\mathrm{S}$ and 5 which affect the success rate of the recognition. The average computational time for the whole system is found to be 0.452 seconds.

\section{CONCLUSION}

This paper presented an automated license plate recognition system for the application of authenticating cars at the campus entrance of the National Energy University in Malaysia (UNITEN). The proposed system is based on the technique of template matching and consists of three main stages: plate localization, character segmentation, and character recognition. In terms of system performance, the accuracy rates for the plate recognition, character segmentation, and character recognition are $91.58 \%, 93.11 \%$ and $80.25 \%$, respectively. This performance might be affected by complex backgrounds in the input images and in cases where there are texts written on the front of the vehicle. In addition, characters that are close to each other will be mistakenly segmented as one character, and mismatches can occur in the recognition stage due to similarities between the characters. The average computational time for the whole system is found to be 0.472 seconds. While this study focuses on auto-gate LPR system, the main limitation of the proposed methods is that it can only recognize a signle plate number at a time (the nearest to the auto-gate). The proposed framework in this study can be extended by using multi-plate localization approach which will be significantly useful in other LPR applications

\section{REFERENCES}

[1] M. Carvalho, "No. 6 on the world's top car theft list," 2016.

[2] Road Transport Department, "Peraturan Reka Bentuk Nombor Plat," 2020.

[3] F. Damayanti, S. Herawati, F. M. Ayu, and A. Rachmad, "Indonesian license plate recognition based on area feature extraction," Telkomnika, vol. 17, no. 2, pp. 620-627, 2019.

[4] S. F. AG, "Development of portable automatic number plate recognition (ANPR) system on Raspberry Pi," Int. J. Electr. Comput. Eng., vol. 9, no. 3, p. 1805, 2019.

[5] P. Marzuki, A. R. Syafeeza, Y. C. Wong, N. A. Hamid, A. N. Alisa, and M. M. Ibrahim, "A design of license plate recognition system using convolutional neural network.," International Journal of Electrical \& Computer Engineering (IJECE), vol. 9, no. 3, pp. 2088-8708, 2019.

[6] W. W. Keong, V. Iranmanesh, "Malaysian automatic number plate recognition system using Pearson correlation," in 2016 IEEE Symposium on Computer Applications \& Industrial Electronics (ISCAIE), pp. 40-45, 2016.

[7] P. Comelli, P. Ferragina, M. N. Granieri, and F. Stabile, "Optical recognition of motor vehicle license plates," IEEE transactions on Vehicular Technology., vol. 44, no. 4, pp. 790-799, 1995.

[8] M. Sarfraz, M. J. Ahmed, and S. A. Ghazi, "Saudi Arabian license plate recognition system," in 2003 International Conference on Geometric Modeling and Graphics, pp. 36-41, 2003.

[9] C. Wu, L. C. On, C. H. Weng, T. S. Kuan, and K. Ng, "A Macao license plate recognition system," in 2005 International Conference on Machine Learning and Cybernetics, vol. 7, pp. 4506-4510, 2005. 
[10] S. Ozbay and E. Ercelebi, "Automatic vehicle identification by plate recognition," World Acad. Sci. Eng. Technol., vol. 9, no. 41, pp. 222-225, 2005.

[11] M. I. Khalil, "Car plate recognition using the template matching method," Int. J. Comput. Theory Eng., vol. 2, no. 5, p. 683, 2010.

[12] R. Sharma, "Automatic license plate based smart vehicle validation \& security by gate control \& email send," IEEE Int. J. Comput. Sci. Inf. Technol., vol. 6, 2015.

[13] A. Tahir, H. A. Habib, and M. F. Khan, "License plate recognition algorithm for Pakistani license plates," Can. J. Image Process. Comput. Vis., vol. 1, no. 2, pp. 30-36, 2010.

[14] S. Rasheed, A. Naeem, and O. Ishaq, "Automated number plate recognition using hough lines and template matching," in Proceedings of the World Congress on Engineering and Computer Science, vol. 1, pp. 24-26, 2012.

[15] D. Gilly and K. Raimond, "License plate recognition-a template matching method," 2013.

[16] M. Z. Siam, "Practical Design of an Automatic License Plate Recognition Using Image Processing Technique," International Journal of Engineering and Innovative Technology (IJEIT), vol. 4, no. 4, pp. 170-179, 2014.

[17] H. Karwal and A. Girdhar, "Vehicle number plate detection system for indian vehicles," in 2015 IEEE International Conference on Computational Intelligence \& Communication Technology, pp. 8-12, 2015.

[18] H. E. Khodke, B. K. Patil, and Y. R. Nagargoje, "Pattern Matching and Analysis of Vehicle Number Plate's Recognition System Using Template Matching,” Int. J. Res. Appl. Sci. Eng. Technol., vol. 4, no. 5, pp. 881-887, 2016. (Penulis beda sama yang di scholar)

[19] M. Abdullah, M. A. H. Bakhtan, and S. A. Mokhtar, "Number Plate Recognition Of Malaysia Vehicles Using Smering Algorithm," Sci. Int.(Lahore), vol. 29, no. 4, pp. 823-827, 2017.

[20] S. Draghici, "A neural network based artificial vision system for licence plate recognition," Int. J. Neural Syst., vol. 8, no. 1, pp. 113-126, 1997.

[21] C. Anagnostopoulos, E. Kayafas, and V. Loumos, "Digital image processing and neural networks for vehicle license plate identification," J. Electr. Eng., vol. 1, no. 2, pp. 2-7, 2000.

[22] V. Ganapathy and W. L. D. Lui, "A Malaysian vehicle license plate localization and recognition system," J. Syst. Cybern. Informatics, vol. 6, no. 1, p. 4, 2008.

[23] A. Broumandnia and M. Fathy, "Application of pattern recognition for Farsi license plate recognition," ICGST Int. J. Graph. Vis. Image Process., vol. 5, no. 2, pp. 25-31, 2005.

[24] O. O. Khalifa, S. Khan, M. R. Islam, and A. Suleiman, "Malaysian Vehicle License Plate Recognition.," Int. Arab J. Inf. Technol., vol. 4, no. 4, pp. 359-364, 2007.

[25] W. Wanniarachchi, D. U. J. Sonnadara, M. K. Jayananda, "License plate identification based on image processing techniques," in 2007 International Conference on Industrial and Information Systems, pp. 373-378, 2007.

[26] S. Saunshi, V. Sahani, J. Patil, A. Yadav, and S. Rathi, "License Plate Recognition Using Convolutional Neural Network," IOSR J. Comput. Eng, pp. 28-33, 2017.

[27] H. Caner, H. S. Gecim, and A. Z. Alkar, "Efficient embedded neural-network-based license plate recognition system," IEEE Trans. Veh. Technol., vol. 57, no. 5, pp. 2675-2683, 2008.

[28] F. Öztürk and F. Özen, "A new license plate recognition system based on probabilistic neural networks," Procedia Technol., vol. 1, pp. 124-128, 2012.

[29] V. Mai, D. Miao, and R. Wang, "Vietnam license plate recognition system based on edge detection and neural networks," Journal of Information and Computing Science, vol. 8, no. 1, pp. 27-40, 2013.

[30] S. Vijayarani and M. Vinupriya, "Performance analysis of canny and sobel edge detection algorithms in image mining," Int. J. Innov. Res. Comput. Commun. Eng., vol. 1, no. 8, pp. 1760-1767, 2013.

[31] R. Maini and H. Aggarwal, "Study and comparison of various image edge detection techniques," Int. J. image Process., vol. 3, no. 1, pp. 1-11, 2009. 